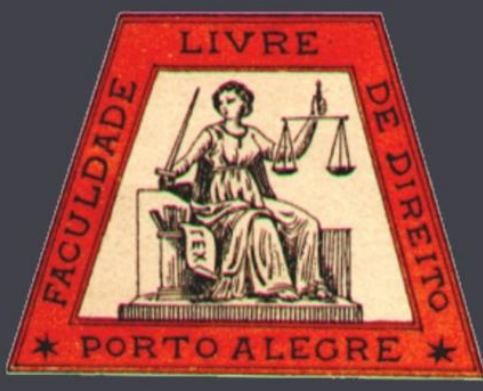

\title{
Reforma agrária e o acesso à terra como um direito humano para as famílias rurais nos países do MERCOSUL: uma análise comparada constitucional e agrarista
}

\begin{abstract}
Agrarian reform and the access to land as a human right for rural families in the MERCOSUL countries: a constitutional and agrarian comparative analysis
\end{abstract}

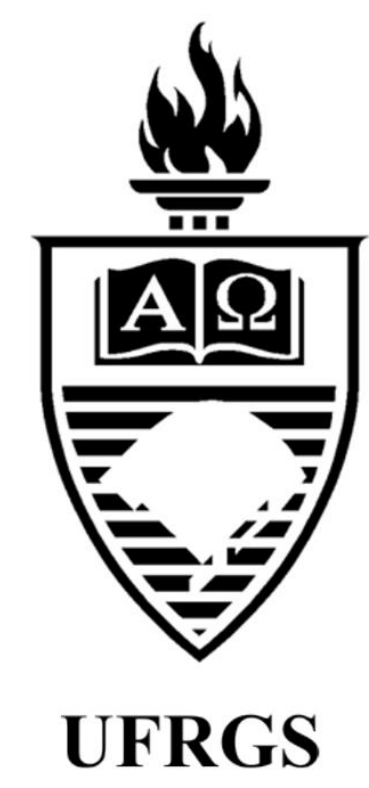

Arthur Ramos do Nascimento Universidade Federal da Grande Dourados

Felipe Borges de Souza Domingues Universidade Federal da Grande Dourados 


\title{
Reforma agrária e o acesso à terra como um direito humano para as famílias rurais nos países do MERCOSUL: uma análise comparada constitucional e agrarista
}

\author{
Agrarian reform and the access to land as a human right for rural families in the MERCOSUL \\ countries: a constitutional and agrarian comparative analysis
}

Arthur Ramos do Nascimento*

Felipe Borges de Souza Domingues ${ }^{* *}$

\begin{abstract}
REFERÊNCIA
NASCIMENTO, Arthur Ramos do; DOMINGUES, Felipe Borges de Souza. Reforma agrária e o acesso à terra como um direito humano para as famílias rurais nos países do MERCOSUL: uma análise comparada constitucional e agrarista. Revista da Faculdade de Direito da UFRGS, Porto Alegre, n. 35, p. 155-177, dez. 2016.
\end{abstract}

\section{RESUMO}

O presente artigo traz ao debate nacional elementos iniciais para reflexão sobre a forma como os países do MERCOSUL encaram o tema da Reforma Agrária e o acesso à terra dentro de uma perspectiva de direitos humanos. Inicialmente analisando o MERCOSUL enquanto um processo de integração e de desenvolvimento regional, a pesquisa apresenta nuances históricas e sociológicas dos países sul-americanos como forma de compreensão da realidade agrária e dos movimentos campesinos pela luta do campo. A partir daí, observa-se a discussão da Reforma Agrária nos países do MERCOSUL, as peculiaridades e diferenças nacionais. A abordagem sobre os direitos humanos e a concepção nacional dos Estados-Membros permite identificar que a proximidade não se limita apenas à questão geográfica, mas que os países compartilham uma identidade muito próxima de concepções e organização, consideradas as devidas proporções e peculiaridades. Assim, é possível analisar as políticas adotadas pelos países membros do MERCOSUL no sentido do acesso à terra como um direito humano e a importância da Reforma Agrária para o desenvolvimento econômico e social. Constata-se a fragilidade das políticas comuns e a ausência de políticas efetivas que incidam sobre todos os países do MERCOSUL, identificando-se ações articuladas, mas sem o status de uma política supraestatal que poderia alcançar maior efetividade para a realidade das famílias rurais.

\section{ABSTRACT}

This article contributes to the national debate bringing initial elements for reflection on how the Mercosur countries view the issue of Agrarian Reform and access to land within a perspective of human rights. Initially analyzing Mercosur as a process of integration and regional development, the research shows historical and sociological nuances of the South American countries as a way of understanding the agrarian reality and peasant movements struggling in the countryside. Since then, it was examined the discussion of land reform in the Mercosur countries, their national peculiarities and differences. The approach on human rights and the national conception of each Member State allows the identification that their proximity is not limited to the geographical issue, but that each country shares close concepts and organization, considering its own dimension and peculiarities. Thus, it is possible to analyze the policies adopted by the MERCOSUL member countries in the sense that the access to land is a human right and the importance of Agrarian Reform to economic and social development. It is noted the fragility of common policies and the absence of effective policies concerning all the countries of MERCOSUL. Joint actions are identified, but without the status of a supranational policy that could achieve greater effectiveness to the reality of rural families.

\footnotetext{
* Professor da Universidade Federal da Grande Dourados. Mestre em Direito Agrário pela Universidade Federal de Goiás, 2012. Especialista em Direito Civil e Processo Civil pela Pontifícia Universidade Católica de Goiás, 2008). Graduado em Direito (Pontifícia Universidade Católica de Goiás, 2006.

** Graduando em Direito pela Universidade Federal da Grande Dourados.
} 
PALAVRAS-CHAVE

Acesso à terra. Direitos Humanos. MERCOSUL. Reforma Agrária comparada.

\section{KEYWORDS}

Access to land. Human Rigths. MERCOSUL. Agrarian reform compared.

\section{SUMÁRIO}

Introdução. 1. O Mercado Comum do Sul e os contornos do desenvolvimento regional sul-americano. 2. Reforma Agrária no MERCOSUL. 2.1 Reforma Agrária no Brasil. 2.2 Concepção de Reforma Agrária na Argentina. 2.3 A Reforma Agrária no âmbito do Paraguai. 2.4 A Reforma Agrária na Venezuela. 3. Direitos Humanos no MERCOSUL. 4. Acesso a terra como Direito Humano e políticas no MERCOSUL. Considerações finais. Referências.

\section{INTRODUÇÃO}

A preocupação com o desenvolvimento tem se ampliado no Brasil e em outros países da América do Sul, o que se verifica com a valorização de movimentos sociais campesinos e de Reforma Agrária. Soma-se a essa tendência a busca pelo desenvolvimento social sustentável, preocupações ambientais, direitos trabalhistas e direitos sociais que cada vez ganham mais espaço nos debates jurídicos.

O discurso (pretensamente) universalizante dos Direitos Humanos implica no reconhecimento reiterado da impossibilidade do Direito em ter todas as respostas diante das situações originais que se apresentam em razão da globalização (fenômeno ainda não perfeitamente compreendido pela seara jurídica). Assim, a globalização, enquanto fenômeno que influenciou os processos de reorganização política, econômica e social (talvez até mesmo as perspectivas filosóficas da modernidade), gerou nas relações internacionais mudança de internação e comportamento. A aproximação de países vizinhos (fenômeno do regionalismo) é uma de suas consequências mais marcantes e fonte de problemas não solucionáveis pelo Direito tradicionalmente posto. ${ }^{1}$
O Brasil está inserido com relativo protagonismo no âmbito da América do Sul, liderando a formação do bloco econômico do MERCOSUL (Mercado Comum do Sul), sendo um dos principais entusiastas de que esse bloco possa se desenvolver e assumir mais relevância na política internacional. A existência de um bloco econômico gera consequente demanda de uniformização de procedimentos, além de estreitamento entre os países membros para além da questão puramente econômica e comercial; passa-se a enfrentar também problemas comuns aos Estados-Membros.

Por força da história recente (colonial e póscolonial) dos países sul-americanos, especialmente dos países membros do MERCOSUL, a questão agrária é um ponto comum entre eles. $\mathrm{O}$ acesso à terra, a valorização do homem do campo, da produção familiar, a proteção dos povos tradicionais, são preocupações coletivas quando pensamos nos países do bloco. Como se observa, a compreensão das demandas dos países integrantes tem o condão de possibilitar a reflexão de estratégias comuns, políticas públicas internacionais, culminando no fortalecimento e no desenvolvimento regional.

A principal questão abordada nessa pesquisa é uma análise inicial da Reforma Agrária a nível de América do Sul, usando como recorte

\footnotetext{
${ }^{1}$ Nas palavras de Pierre Pescatore trata-se de uma situação sem precedentes para as fórmulas jurídicas (que não respondem esses problemas): "Princípios, normas e instituições são explícita ou implicitamente questionadas pelos atores de um processo que não podem ser detidos ante as deficiências ou insuficiências do direito. Com imaginação e força criadora, estadistas e juristas associaram-se para desenhar marcos jurídicos e institucionais funcionais com vista às exigências de agora." (1973, p. VII)
} 
geográfico e político o MERCOSUL. Dessa forma, os aspectos trazidos nessa pesquisa se inserem na seara jurídica como uma proposta interdisciplinar, abordando preocupações do Direito Agrário, Direitos Humanos e Direito ao Desenvolvimento, bem como acrescendo novas visões iniciais para proposições de Direito Internacional. Trata-se de um olhar de pesquisas iniciadas no âmbito acadêmico, amplificando os debates jurídicos acerca dos temas aqui desenvolvidos, além de tentar, na medida do possível, fomentar a evolução do Direito e dos países sul-americanos.

Procedeu-se à pesquisa bibliográfica com levantamento e análise de dados, tanto nacionais quanto internacionais, nas constituições nacionais dos países do MERCOSUL, em dissertações e trabalhos acadêmicos desses Estados, em literatura especializada, além de publicações de órgãos e organizações oficiais, bem como foi utilizado o aporte legal de legislação pertinente de cada nação mencionada.

Empregou-se o método hipotético dedutivo para, após a leitura e reflexão sobre os conteúdos dos materiais de pesquisa, alcançar-se uma teoria que aponte para soluções, ou mesmo novos questionamentos, em relação ao acesso à terra através da Reforma Agrária como um Direito Humano para as famílias rurais latinoamericanas.

Iniciou-se a análise com o estudo da realidade do MERCOSUL, país a país, levando à problematização da Reforma Agrária nessas

\footnotetext{
${ }^{2}$ Conforme leciona Karina Pasquariello Mariano, citando as palavras de Held e McGrew, podemos entender a globalização como uma "mudança ou transformação na escala da organização social que liga comunidades distantes e amplia o alcance das relações de poder nas grandes regiões e continentes do mundo". A autora (2007, p. 124) também destaca que se trata de um conceito não unívoco nem consensual sobre seus impactos e significado. É possível refletir sobre o fenômeno a partir de relações de comércio, fluxos de capital e pessoas, limitando distâncias e tempo de organização e interação social.

${ }^{3}$ É necessário destacar que a sigla do bloco econômico também pode ser encontrada como MERCOSUR (Mercado
}

nações. Na sequência, foram escolhidos os Estados a serem analisados de forma extensa, utilizando como parâmetro o Brasil. Passou-se, então, às considerações sobre a dimensão dos Direitos Humanos e do acesso à terra como um direito fundamental para as famílias campesinas para, por fim, indagar como a Reforma Agrária é instrumento de efetivação desses direitos.

Como destacado o MERCOSUL é um bloco econômico ainda jovem e que demanda continuadas pesquisas para sua melhor compreensão e desenvolvimento. De igual forma, o presente trabalho de pesquisa não se pretende exaustivo ou mesmo conclusivo sobre questões envolvendo a Reforma Agrária no MERCOSUL, especialmente em face das multifacetadas possibilidades de abordagem do bloco. Pretendese fomentar um novo olhar frente a possíveis políticas estatais na América do Sul que permitam compreender que o acesso à terra é um Direito Humano fundamental.

\section{O MERCADO COMUM DO SUL E OS CONTORNOS DO DESENVOLVIMENTO REGIONAL SUL-AMERICANO}

A partir do século XX, com o advento da Globalização $^{2}$, vários países passaram a se unir buscando a integração econômica, o que originou diversos blocos econômicos, como o Mercado Comum do Sul - MERCOSUL ${ }^{3}$, o Nafta e a União Europeia. ${ }^{4}$ Ao participar dessa união, pretendia-se superar diferenças regionais e nacionais, visando

Común del Sur, em castelhano), ou mesmo em guarani $\tilde{N} e m b y \tilde{N} e m u h a$ (mas essa forma é menos usual). A despeito dessas considerações o trabalho adotará a forma oficial no Brasil.

4 Não é objetivo do presente ensaio apresentar contextualizações e conceitos dos blocos econômicos, cabe apenas esclarecer que o NAFTA (do original, em inglês North American Free Trade Agreement) é o Tratado NorteAmericano de Livre Comércio formado por Canadá, México e Estados Unidos (o Bloco possui o Chile como um associado), desde 1994. De igual forma a União Europeia é o principal modelo de integração regional e econômica 
ganhos para todos os participantes do bloco e fortalecendo a relações econômicas por ações em conjunto dentro e através desses blocos. Contudo, uma das desvantagens em associar-se sempre foi o fato de que cada Estado possui suas particularidades que, não raramente, divergiam ou mesmo iam de encontro aos preceitos de outra nação. Isso se deve aos diversos processos de formação histórica, econômica, política, social e cultural que se desenvolveram em diferentes espaços e tempos, resultando em países com as mais variadas concepções, modos de vida e objetivos.

Atualmente, não é com grande surpresa que se observa a intenção de avançar ainda mais na integração entre os países participantes e superar o obstáculo supracitado. Assim como há diferenças, também podem ser encontradas semelhanças (ambas nas dimensões históricas, políticas, culturais, às vezes linguísticas, religiosas, econômicas etc.). Utilizando isso em seu favor, os diversos blocos econômicos passaram a estipular políticas públicas, diretrizes, objetivos, dentre outros, a seus associados com a intenção de estabelecer um patamar comum, não somente no aspecto econômico, mas também social e político; pois, identificando problemas universais, incentiva-se a troca de informações e a cooperação, que por sua vez incita e reforça o(s) vínculo(s) entre os Estados e, consequentemente, fortalece o bloco como um todo.

É importante destacar o caráter multidimensional desse regionalismo, onde a integração não se limita a ser um mecanismo de abertura comercial, mas de inserção estratégica internacional também com conotações políticas e econômicas. É possível dizer que participar de um processo de integração (formação de um bloco econômico) é mais importante até mesmo que os resultados concretos. Aqui, cabe destacar que quando tratamos dos processos de integração da
América Latina “o discurso governamental em defesa dessas estratégias integracionistas baseiase numa visão identificada com a coesão regional" onde "o Mercosul coloca como uma de suas finalidades a aproximação dos Estados como forma de estabelecer uma identidade comum perante o resto do mundo" também na defesa da "cooperação e a integração como o instrumento eficaz para a promoção do seu desenvolvimento" (MARIANO, 2007, p. 137). Nesse sentido, também, o MERCOSUL se consagra como um processo de integração prioritariamente ligado aos temas comerciais (voltado ao "mercantilismo", como é costumeiramente referido no debate político), além de ser um processo intergovernamental (limitado aos governos de cada Estado) (VENTURA; ROLIM, [200-], p. 1).

Iniciado com a assinatura do Tratado de Assunção pelos países da Argentina, Brasil, Paraguai e Uruguai, em 26 de março de 1991, esse bloco econômico é um projeto político e estratégico que tenta promover a integração das nações latino-americanas, a começar pelos Estados da América do Sul. Seus objetivos principais são a união política, econômica e social entre os seus membros, promovendo a qualidade de vida ao mesmo tempo em que fomenta o desenvolvimento de vínculos entre seus cidadãos. Para atingir esses objetivos, pretende-se estabelecer a livre circulação de bens e serviços, estipular uma política comercial e uma Tarifa Externa Comum (TEC), coordenar políticas macroeconômicas e setoriais e harmonizar as legislações no que for pertinente (MERCOSUL, [s.d.], não paginado). Dessa forma:

Em resumo, o Mercosul não se limita à dimensão econômica e comercial, contando com iniciativas comuns que abrangem da infraestrutura às telecomunicações; da ciência e tecnologia à educação; da agricultura familiar ao meio ambiente; da cooperação fronteiriça ao combate aos ilícitos 
transnacionais; das políticas de gênero à promoção integral dos direitos humanos. Isso é o que faz do MERCOSUL um dos projetos de integração mais amplos do mundo. (MINISTÉRIO DAS RELAÇÕES EXTERIORES, [s.d.], não paginado)

No presente, o MERCOSUL possui como membro, além dos países originais de 1991, a Venezuela. A Bolívia se encontra em processo de adesão como Estado membro, enquanto Chile, Colômbia, Equador, Guiana, Peru e Suriname participam como Estados associados. É possível notar que a integração de países com proximidade geográfica e que possuem um passado histórico similar pode representar, no futuro, $\mathrm{o}$ desenvolvimento econômico e social dessas nações. Entretanto, as similitudes desses países implicam também na necessidade de se enfrentar problemas comuns a todos por meio de políticas públicas que beneficiem a todos os membros.

Nesse âmbito, um dos problemas em comum a todos os países é a questão Agrária. ${ }^{5}$ Sua importância é claramente delineada ao se observar que diversos Estados, separadamente ou através do MERCOSUL, pautam suas ações e políticas públicas visando promover a pacificação social no campo ao buscar a possibilidade do acesso à terra e a fixação no campo das famílias rurais, a justa distribuição de terra para os trabalhadores e promover o desenvolvimento agrário como um todo (não somente no sentido econômico). Importante notar que a atenção especial voltada

\footnotetext{
${ }^{5}$ Em linhas gerais, pode-se esclarecer que a questão agrária envolve a concentração da propriedade da terra e do poder político e econômico nos espaços agrários, gerando o desenvolvimento capitalista e o empobrecimento e enfraquecimento do campesinato, bem como institutos como a desapropriação, demarcação de terras (para indígenas e quilombolas). A questão agrária está ligada com a população campesina e o trabalho de produtores rurais. Assim, nas palavras de Guilherme G. Télles Bauer a questão agrária "tem sua origem nos debates travados no interior do movimento operário europeu na passagem do século, procurando esclarecer como se dava a penetração do capitalismo no campo e buscando apontar estratégias para uma aliança do movimento operário com o campesinato, na luta para derrubar as estruturas feudais prevalecentes no meio rural. Hoje, o termo vem sendo utilizado no âmbito
}

aos indígenas, comunidades tradicionais, a cautela com os impactos da dinâmica do desenvolvimento tecnológico e a proteção do trabalhador frente à mecanização são pautas discutidas globalmente, não somente a nível nacional ou de alguns Estados.

De modo geral, os conflitos relacionados à terra integram o processo histórico, econômico e políticos de todos os países sul-americanos, eis que sua posse demonstra, desde tempos passados, à proximidade com o Governo, o poderio econômico ou a força de armas. Diante da monopolização de terras, surgiu a concepção da Reforma agrária como instrumento de rompimento do sistema vigente no campo, possibilitando a democratização de seu acesso e, consequentemente, promovendo a Justiça Social no âmbito rural (FERREIRA, 2002, p. 150). Por óbvio que, por atingir diretamente o interesse de pessoas com realce social, proeminência financeira ou com estreitas ligações políticas, buscou-se sufocar e repreender essas reinvindicações por igualdade e direitos fundamentais para aqueles situados no campo. A América do Sul, em seu processo histórico, foi marcadamente influenciada pelo poder oligárquico de coronéis e grandes proprietários de terra, o que influenciou na resistência às transformações (ou ao próprio desenvolvimento) da Reforma Agrária. ${ }^{6}$

das ciências sociais e pelos organismos e instituições internacionais, que se preocupam com a problemática do atraso, sobretudo no sentido de discernir e apontar saídas para os gravíssimos problemas da crescente miséria e do subdesenvolvimento que caracterizam o setor rural dos países periféricos." (1998, p. 136)

${ }^{6}$ Nesse sentido, Sérgio Pereira Leite e Rodrigo Vieira de Ávila em seu artigo "Reforma agrária e desenvolvimento na América Latina: rompendo com o reducionismo das abordagens economicistas" abordam a questão do acesso à terra e o desenvolvimento da América Latina a partir da reforma agrária e, citando Maria da Conceição Tavares (1996), "da perspectiva do pensamento reformista latinoamericano dos anos 50 e 60, a reforma agrária era concebida como um processo social inserido em um movimento global de transformação da sociedade e direcionado a três 
Com a redistribuição da posse de terras através da Reforma Agrária, promove-se a "libertação" das famílias rurais da submissão em relação aos latifundiários, porquanto fornece a possibilidade de, com o acesso a terra, buscar-se o sustento alimentar, o desenvolvimento econômico e, por conseguinte, almejar a melhores condições de vida. Ademais, é inquestionável a relação diferenciada que os trabalhadores do campo possuem com a terra, eis que esta não se apresenta somente como propriedade (terra, espaço físico com medida determinada ou mero bem passível de compra e venda), mas também como parte de sua própria identidade e modo de vida. Tal vínculo estreito é observado em todo âmbito latino-americano, especialmente pela forte presença de povos tradicionais em suas sociedades.

Posto isso, aponta-se o processo histórico ${ }^{7}$ da Reforma Agrária e como o Acesso à Terra, um de seus principais pressupostos, deve ser compreendido como um Direito Humano para as famílias rurais. Aliás, embora tenha se evitado, em razão de espaço e tempo, aprofundar na análise detida de cada Estado membro ou associado do MERCOSUL ou na gênese e expansão da luta desenvolvida pelos movimentos sociais, faz-se uma exposição histórica e constitucional que englobe a totalidade, eis que é impossível entender a dinâmica desse bloco econômico e, por conseguinte, a Reforma Agrária

\footnotetext{
objetivos estratégicos: a ruptura do poder político tradicional (democratização), a redistribuição da riqueza e da renda (justiça social) e a formação do mercado interno (industrialização). No caso brasileiro, as transformações ocorridas no campo durante as décadas de 1960 e 1970 [...] e o marco político-ideológico que se consolidou [...] conduziram a um progressivo reducionismo na concepção da reforma agrária, que foi redefinida [...] como um instrumento de 'política de terras. A 'revolução agrícola' [...] desativou' o significado econômico clássico da reforma (a formação do mercado interno), contribuindo assim para a afirmação da concepção reducionista". E segue Maria da Conceição Tavares lembrando que as "transformações das bases técnicas e econômicas" não tiveram correspondência
}

na América do Sul, sem compreender suas diferenças e similitudes.

Isso se faz necessário, pois, para a efetiva cooperação entre os povos e a criação de uma comunidade latino-americana, é imprescindível solucionar, de fato, a questão agrária no cenário latino-americano, o que só poderá ser alcançado com a Reforma Agrária, apresentando-se como um desafio constitucional complexo e necessário.

\section{REFORMA AGRÁRIA NO MERCOSUL}

Apesar de compreender uma vasta extensão territorial (cerca de $12.789 .558 \mathrm{~km}^{2}$, contando somente os países membros), os diversos Estadosmembros do MERCOSUL desenvolveram-se de forma semelhante, seja na política, economia ou história. Ora, foram países colonizados unicamente para extração e exploração de seus recursos, sendo comandados por aqueles escolhidos pelo monarca em razão de destaque econômico ou proximidade com o governante. Posteriormente, já como nações independentes, passaram a depender exclusivamente de suas terras, com exceção de poucos que sustentavam sua balança econômica através de meios alternativos às produções agrárias, fato este que se estende até tempos atuais. Acrescentando-se a isso o problema de distribuição e disputa de terras, a inércia legislativa juntamente com má gestão política, nascidos desde a colonização de cada país, e surgirá um pequeno resumo da questão

nos outros planos: "A terra e a riqueza continuaram sendo concentradas por força dos novos interesses agroindustriais, da expansão da fronteira e dos interesses agrários tradicionais [...]." E, depois de lembrar que a terra "mantém [...] notável importância econômica e política", conclui: "a confluência no campo de dois processos - a modernização conservadora da produção e o agravamento dos fatores de exclusão nas áreas tradicionais e de fronteira - tende a tornar mais crítica a questão da terra." (2007, p. 779-780)

${ }^{7}$ Dadas as dimensões de um artigo acadêmico esse processo histórico não será analisado com profundidade, apontandose apenas o essencial para a compreensão da proposta da pesquisa. 
agrária das nações sul-americanas. Logo, essa problematização da má exploração e distribuição da terra, com as mazelas sociais decorrentes dessa questão, está presente na história da América do Sul.

A origem da questão agrária, especialmente no que tange à distribuição da propriedade da terra, é um tema controvertido. Poder-se-ia creditar à forma de colonização empregada nos países como a principal origem da crise agrária. Isso decorreria do senso de exploração pura e desenfreada, incentivando a tomada de terras e a utilização da violência a mando econômico ou político (ou ambos) para agregar e manter propriedades. Por outro lado, o meio como ocorreram as colonizações também é plausível para explicar as disparidades rurais. Nesse sentido, a utilização de sesmarias no Brasil ou a detenção de terras pelo Governo e sua posterior venda a Estados estrangeiros na Argentina, como exemplos, teria fomentado a mercantilização e, por conseguinte, o desigual acesso e aquisição de propriedades. Obviamente, é cristalino o fato de que ambas as situações, somadas à política de valorização do poder político e econômico (que implicou no favorecimento de determinados grupos), na má distribuição dos investimentos (desenvolvendo certa região em detrimento do país) e na resolução de conflitos através de embates sangrentos (forças armadas, comunidades tradicionais e camponeses), gestaram uma realidade contemporânea preocupante para o espaço agrário do MERCOSUL.

Nesse sentido, cabe observar que:

[C]ada indivíduo, ou grupo social, se valoriza pelo desenvolvimento contínuo de suas potencialidades, na medida em que se abre a todos os outros, neles reconhecendo o complemento necessário de si próprio". (COMPARATO, 2006, p. 699)

Essa perspectiva de reconhecimento do "outro" como verdadeiro exercício de alteridade entre Estados é essencial para alcance do desenvolvimento coletivo do bloco, como assinalado. $\mathrm{O}$ espaço agrário é facilmente identificado como um dos aspectos de desenvolvimento dos países latino-americanos que comprovam suas vocações agraristas (agropecuárias), sendo também um de seus pontos fortes na política econômica mundial.

É imprescindível a formulação, ou reformulação em certos casos, e implantação efetiva da Reforma Agrária no sul da América para que seja possível sanar distorções e reverter injustiças históricas, proporcionando o desenvolvimento no campo e consequentemente impulsionando a sociedade urbana, fomentando o avanço nacional. É imprescindível aproveitar-se dos fatores comuns entre os membros $\mathrm{e}$ associados do MERCOSUL, lançando mão do auxílio mútuo para essa evolução dos povos sulamericanos. As reformas agrárias na América Latina só foram possíveis por causa das mudanças significativas ocorridas no âmbito político dos países onde se desenvolveram, contrariando a noção comum de se tratar de uma resposta à pressão social exercida pelos camponeses e movimentos sociais para terem acesso à terra. Contudo, a reivindicação de direitos, certamente, foi fundamental para materialização das ações de reforma (CONCHOL, 2003, p. 211-212). É essencial compreender o que é a reforma agrária, em seu sentido amplo e como se desenvolveu em alguns Estados em destaque, e reconhecer o acesso à terra como um direito fundamental a toda e qualquer pessoa, para que se possa discutir políticas em comum, buscando a Justiça Social no contexto do MERCOSUL.

\subsection{Reforma Agrária no Brasil}

Pois bem, o Brasil construiu a maior parte de seu processo histórico calcado na dependência de bens produzidos no âmbito agrário. Porém, buscando autonomia das velhas oligarquias rurais, Getúlio Vargas, presidente eleito em plena 
política do Café com Leite e pelos mesmos grupos agrários que posteriormente buscou libertar-se, promoveu a industrialização brasileira em seu primeiro governo (1930 a 1945). Como consequência, ocorreu a valorização da indústria e das cidades, estas como sinônimos de progresso e desenvolvimento, enquanto o campo e as produções agrícolas sofreram seriamente pela desvalorização, influindo negativamente na qualidade de vida da população campesina. Resultado disso, surgiu o êxodo rural (massiva evasão dos campos para as cidades) que acabou por superpopular os centros urbanos, os quais não detinham estrutura suficiente a comportar esse excesso populacional. Como se não bastasse disseminou-se o discurso de que o campo era o símbolo do atraso e a cidade impulsionada pela indústria representava o progresso. Entretanto, a parcela populacional restante que ainda vivia no campo, auxiliados por intelectuais, políticos, os recém-nascidos movimentos sociais e setores da esquerda, passaram a reivindicar ações e posicionamentos dos legisladores com o objetivo de regularizar a situação agrária, que compreendia desde o total descontrole quanto à ocupação e posse de terras até a implementação de políticas governamentais com o escopo de promover o desenvolvimento social e econômico agrário.

Em meio a esse caos social e político marcado pelos embates (ideológicos e violentos), foi editada a Lei 4.504/64, o Estatuto da Terra, que pela primeira vez introduziu o conceito de Reforma Agrária na legislação brasileira. Em seu Art. $1^{\circ}, \S 1^{\circ}$, declara que: "Considera-se Reforma Agrária o conjunto de medidas que visem a promover melhor distribuição da terra, mediante modificações no regime de sua posse e uso, a fim de atender aos princípios de justiça social e ao aumento de produtividade." Nesse mesmo texto legal, introduziu-se a função social da propriedade rural, pedra de toque na discussão sobre a Reforma Agrária, tratada da seguinte maneira:
A propriedade da terra desempenha integralmente sua função social quando: a) favorece o bem estar dos proprietários e dos trabalhadores que nela labutam, assim como de suas famílias; b) mantém níveis satisfatórios de produtividades; c) assegura a conservação dos recursos naturais; d) observa as disposições legais que regulam as justas relações de trabalho entre os que a possuem e a cultivam.

Infelizmente, mesmo a edição desta lei não foi o suficiente para que a proposta de Reforma Agrária pudesse tomar forma e efeito, sendo totalmente negada sua aplicação pelo Regime Militar (MARÉS, 2010, p. 191).

Somente com a Constituição da República Federativa do Brasil de 1988 a Reforma Agrária ganhou o destaque necessário em plano nacional ao ser expressamente descrita e regulada pela Carta Magna dentro do Título VII - Da Ordem Econômica e Financeira, Capítulo III - Da Política Agrícola e Fundiária e da Reforma Agrária, especificamente pelos artigos 184 à 191, demonstrando a máxima atenção dada ao tema pela constituinte. Novamente, positivou-se a função social da propriedade rural, elencando requisitos a serem atendidos cumulativamente, quais sejam: o aproveitamento racional e adequado, utilizar os recursos naturais de forma adequada e preservar o meio ambiente, obedecer a legislação trabalhista, bem como explorar a propriedade de modo a favorecer o bem-estar do proprietário e aquele que labutam em suas terras. Somente quando observadas estas quatros exigências, a propriedade rural estará imune à desapropriação para fins de reforma agrária, caso contrário, mediante justa e prévia indenização através de títulos da dívida agrária, a União poderá retirar a propriedade de seu dono. As exceções se apresentam para os casos de propriedade que desenvolvam plantio ou produção de substâncias psicotrópicas ou empreguem mão de obra escrava, situações em que a propriedade será expropriada, sem que nenhuma indenização seja devida ao seu dono. 
Por sua vez, a moderna doutrina brasileira complementa o entendimento sobre a Reforma Agrária, explicando que

[É] todo ato tendente a desconcentrar a propriedade da terra quando esta representa ou cria um impasse histórico ao desenvolvimento social baseado nos interesses pactuados da sociedade. (MARTINS, 1999, p. 107)

Apesar do esforço em implantar a Reforma Agrária, os interesses particulares acabaram por solapar novamente sua materialização, protelando-a em favor do latifúndio e da economia de exportação. Veja o disposto no artigo 185 da Constituição Brasileira: "Art. 185. São insuscetíveis de desapropriação para fins de reforma agrária: [...] II - a propriedade produtiva. Parágrafo único. A lei garantirá tratamento especial à propriedade produtiva e fixará normas para o cumprimento dos requisitos relativos à sua função social." O artigo supramencionado foi adicionado pela pressão exercida pelos latifundiários e seus aliados, praticamente inviabilizando a reforma agrária, eis que basta a propriedade ser produtiva para não ser passível de desapropriação. Certamente, a interpretação mais correta seria a de que o cumprimento da função social deve ser completo, pois a própria Carta Magna é expressa ao afirmar que são requisitos cumulativos. A inércia do Legislativo em regular o disposto no artigo 185 , da CRFB/88, não pode constituir óbice ao direito de milhares de famílias rurais à terra, cabendo ao Judiciário tal tarefa.

Em que pese todas as dificuldades enfrentadas pelo Brasil, melhor sorte não assiste aos outros países do MERCOSUL, conforme passa a se expor.

\subsection{Concepção de Reforma Agrária na Argentina}

A concepção argentina da Reforma Agrária é muito semelhante à brasileira, apresentando-a como a redistribuição ou repartição de terras entre os que habitam o campo. ${ }^{8}$ Configura-se também pela reestruturação agrária acompanhada de uma profunda mudança legislativa, a fim de proporcionar o acesso à terra de forma igualitária, ou seja, um direito há qualquer pessoa que tenha a intenção de cultivá-la. A partir disso, é possível promover o desenvolvimento social e econômico através do aumento e melhoramento da produção agrícola de forma equilibrada, beneficiando tanto as famílias rurais quanto o progresso nacional (CARRERA, 1961, p. 34-36). Segundo Carlos Eduardo Reboratti, a reforma agrária sempre atrai a discussão do "rol social de la tierra" ou do desenvolvimento agrário através da expansão territorial ou intensificação do uso da terra. Apesar de anos discutindo a dinamização rural, a reforma agrária nunca foi efetivada até as últimas décadas do século XX (1989, p. 5).

A concentração da propriedade da terra argentina iniciou-se de forma semelhante à brasileira, na época colonial e com a formação de grandes latifúndios (as "haciendas"). Com a sua independência, em 9 de julho de 1816, esse sistema de monopolização da propriedade rural acabou se enraizando na sociedade da Argentina. Para piorar, passou a ser promovida pelo próprio Estado argentino, utilizando suas forças armadas para massacrar inúmeras comunidades indígenas visando a expansão e colonização de novas terras, posteriormente vendendo-as, ou somente entregando, a financiadores $\mathrm{e}$ investidores internacionais. Com o início do século $\mathrm{XX}$, a situação novamente se agravou, eis que os latifúndios que se formaram no século anterior,

Direito Sul-Americano: análises comparadas constitucionais de Brasil e Argentina", ainda não publicado.

${ }^{8}$ Uma pesquisa mais aprofundada com as comparações
entre Brasil e Argentina foi produzido pelos autores com o
título "Reforma Agrária e Função Social da Propriedade no 
passaram a avançar sobre as pequenas propriedades rurais. Outro novo fator a piorar esse momento encontrava-se na utilização de mão de obra de trabalhadores rurais em verdadeiro regime escravistas. Os grandes proprietários formulavam contratos de modo unilateral e voltados exclusivamente a favorecê-los em detrimentos dos campesinos, fosse arrendamento ou prestação de serviços. Novamente, o Estado argentino anuiu ou omitiu-se, no que foi acompanhado pela sua comunidade jurídica e parte da sociedade civil. Nesse ponto, em meio a tal realidade extremamente desumana no âmbito agrário, os primeiros movimentos sociais nasceram, buscando o reconhecimento de seus direitos de acesso, permanência e proteção da terra, o reconhecimento de suas identidades socioculturais e a defesa de seu modo de vida. Como consequência eclodiram diversas conflitos motivados pela terra, muitos com o derramamento de sangue de ambos os lados, além de incentivar a tomada de terras por meio de violência ou, ainda, a "justiça com as próprias mãos" (KOSOVSKY; SOLER, 2004, p. 275-290).

Nada obstante a tudo isso, a questão agrária não foi elevada ao nível constitucional, mormente pela ainda dominante monopolização da terra por latifundiários vinculados aos três poderes da Argentina.

\subsection{A Reforma Agrária no âmbito do Paraguai}

O surgimento da questão agrária no Paraguai remonta ao seu período de guerras, como a Guerra do Paraguai (1864-1870) e a Guerra del Chaco (1932-1935), que acabaram devastando o país. Estima-se que mais da metade da população pereceu, predominantemente a masculina, fosse pelo conflito em si ou pela desestruturação econômica resultante. Por conseguinte, essa desestabilização nacional gerou problemas como a fome e miséria generalizadas, bem como ocorriam paralelamente constantes golpes de Estado. Nesse sentido:

\begin{abstract}
El origen de la estructura latifundista en Paraguay se remonta a la venta masiva de tierras públicas después de la guerra de 1870 las cuales fueron adquiridas en gran parte por capitales extranjeros. Este proceso nunca se revirtió a pesar de las diferentes legislaciones en materia de reforma agraria a partir de 1936. (FYAN Y LA VÍA CAMPESINA, 2004, p. 14)
\end{abstract}

No ano de 1887, o general Bernardino Caballero firmou-se definitivamente no poder, proporcionando a recuperação pós-guerras através da privatização das terras públicas e a retomada da pecuária de exportação. Ademais, ocorriam confiscos em massa de propriedades rurais pertencentes a dissidentes políticos e opositores em geral de Caballero, sendo que as terras tomadas eram arrendadas aos camponeses a título de cultivo obrigatório, proibida a venda. (RIBEIRO, 2012, p. 3). Mesmo na venda de terras rurais a particulares, os moradores do campo tinham preferência na aquisição, porém duas condições de compra praticamente inviabilizavam o acesso à terra pela maioria das famílias rurais: cota mínima de meia légua quadrada e pagamento do valor em espécie. Por tal motivo, ocorreu a concentração da propriedade rural nas mãos daqueles favorecidos pelo regime, mas, contrário senso, não eclodiram conflitos imediatos em razão da monopolização das terras, eis que o país ainda sofria com o baixo número populacional e requisitos básicos de qualidade de vida, sendo que era mais vantajoso mudar-se para outra área do que contestar os latifúndios e o Governo.

Nada obstante, em 1904 o Partido Liberal assumiu a direção do Paraguai, inaugurando novo período marcado por instabilidade política, só que agora dentro do próprio partido, dividido entre cívicos e radicais, enquanto combatiam a possibilidade da retomada do poder pelo Partido Colorado. Em relação ao âmbito agrário, o 
governo de Eligio Ayala (1923-1928) decretou uma lei de reforma agrária em 1926, estabelecendo a desapropriação de propriedade mediante indenização em dinheiro. Porém, a mesma sequer foi utilizada, porquanto foram promovidas políticas públicas de colonização em locais não cultivados. Ainda, tentou-se beneficiar os camponeses distribuindo cerca de duzentos mil hectares a aproximadamente dezessete mil famílias, vedando-lhes vender, arrendar ou hipotecar a porção de terra cedida.

A questão agrária permaneceu esquecida até a ascensão de Alfredo Stroessner em 1954. Além dos latifúndios formados anteriormente estarem intactos, passou a ser priorizada a monocultura de grande porte voltada para a exportação (plantation), resultando no avanço das grandes propriedades sobre a propriedade familiar e de pequeno porte. Nesse contexto, grupos de camponeses começaram a formar ligas agrárias com a intenção de defender suas terras, que por sua vez iniciou a repressão e policiamento no campo. Após a queda de Stroessner, as lideranças dos movimentos camponeses começaram a, além de resistir à tomada de suas terras, ocupar propriedades, em especial as situadas na faixa de fronteira com o Brasil.

A partir de 1994 as organizações camponesas passaram a organizar, reuniões, protestos, marchas, etc., para reivindicar maior apoio do governo em matérias sensíveis ao meio rural, como concessão de crédito, anistia de dívidas, melhores preços, estrutura para escoamento das produções. Em 1999, a ligas agrárias começaram a receber apoio estudantil e da sociedade, demostrando o impacto que a questão agrária estava tendo sobre $\mathrm{o}$ país. Entretanto:

As pressões sobre o campesinato se avolumaram: Podia-se inicialmente tentar comprar sua parcela. Em caso de resistência utilizava-se helicópteros para pulverizar com agrotóxicos a região, ou policiais e jagunços alegando ocupação ilegal das terras passavam a hostilizar os camponeses, matando seus animais, fazendo disparos e em alguns casos matando lideranças camponesas. Lembremos que além da presença de fazendeiros brasileiros, existem entre os proprietários paraguaios poderosos políticos do Partido Colorado, que desfrutam de poder nos meios policiais e judiciais do país. (RIBEIRO, 2012, p. 8-9)

Os camponeses reagiram de variadas formas, alguns fugiram, outros optaram pela luta armada ou judicial. Houve o aumento da ocupação de terras, sobretudo as que possuíam títulos não confiáveis, uma dessas invasões culminou com o Massacre de Caraguaty, resultando na morte de onze camponeses e seis policias, desencadeando a queda do então presidente paraguaio Fernando Lugo. Curioso pontuar que Lugo chegou a presidência buscando dialogar com os movimentos rurais, porém em nenhum momento efetivou políticas públicas voltadas para a reforma agrária, pois a tentativa de acordo era inaceitável para os latifundiários brasileiros e paraguaios.

Importante frisar que a Constituição da República Paraguai de 1992 destina uma seção inteira à Reforma Agrária, nos artigos 114 a 116, bem como trata da função social da propriedade em seu artigo 109. Ao contrário da Argentina e de modo semelhante ao Brasil, a questão agrária foi alcançada a nível constitucional para demonstrar a importância do tema para o desenvolvimento nacional.

\subsection{A Reforma Agrária na Venezuela}

A Venezuela iniciou sua Reforma Agrária, de forma continua, a partir de março de 1960, com a promulgação da Ley de Reforma Agrária. Sua criação e aprovação só foi possível através da união política e da necessidade de contemplar critérios distintos para promover o desenvolvimento social, político e econômico, buscando superar os males do período em que o país esteve sob regime ditatorial (STREDEL, 1973, p. 1). 
Ainda conforme Juan Stredel, o conceito venezuelano de Reforma Agrária é muito semelhante ao adotado pelo Brasil:

La entendemos como un proceso integral de ejecución continua y simultánea, cuyos objetivos son la elevación económica, social, política y cultural de la clase productora marginal (campesinos); mediante la redistribución del ingreso nacional, la transformación del sistema de tenencia de la tierra y la transformación de las instituciones públicas relacionadas con el proceso. (STREDEL, 1973)

O processo de democratização do campo através da reforma estrutural tinha por objetivo acabar com o latifúndio de forma pacífica, lançando mão da aquisição de terra por parte do Estado quando fosse necessário, mediante pagamento em Títulos da Dívida Agrária e redistribuindo as terras para os camponeses de forma gratuita. Além disso, o Governo venezuelano deveria fornecer crédito, assistência técnica, fomentar o desenvolvimento agrário e promover políticas públicas para fixar e auxiliar esses novos proprietários. Com o pesado gasto estatal era de se esperar que a Reforma Agrária venezuelana obtivesse êxito, porém não é o que ocorreu. Enquanto os investimentos aumentavam, a redistribuição de terra e as famílias camponesas assentadas diminuíam. Houve também o aumento do êxodo rural rumo aos centros urbanos mesmo que as condições na cidade não fossem muito melhores às do campo. Isso resultou no aumento da concentração de terras nas mãos dos grandes proprietários, os mesmos que a lei de Reforma Agrária da Venezuela se propôs a extinguir.

O motivo do fracasso da questão agrária venezuelana encontra-se no descaso governamental durante a condução da reforma agrária, ao ignorar seus princípios gerais ou em razão de falhas na execução. Ocorreu da seguinte forma: após realizar o assentamento de famílias rurais através da concessão de porções de terras, não havia o devido acompanhamento por parte do Estado, tais como empréstimos com menor taxa de juros, capacitação de mão de obra rural e a estruturação do escoamento de produção. Por tais motivos, tentou-se alterar a legislação nacional para atender as novas expectativas atrelados ao desenvolvimento rural (meio-ambiente, relações trabalhistas e direitos humanos) além de tentar revitalizar a própria Lei de Reforma Agrária venezuelana para sanar as falhas observadas anteriormente (CORREDOR, 2009, p. 02-04).

Ademais, a Constituição da República Bolivariana da Venezuela de 1999 não faz expressa referência à Reforma Agrária, contudo, estabelece que é obrigação do Estado promover políticas agrícolas, estabelecendo métodos de abordagem para fomentar o desenvolvimento rural, a segurança alimentar, o bem-estar e segurança daqueles que habitam o campo. Importante pontuar que no artigo 307 da Carta Magna venezuelana, é expressamente vedado o latifúndio, eis que "es contrario al interés social".

É possível identificar, como observado, o tratamento dado pelos países componentes do MERCOSUL quanto ao acesso à terra ou mesmo o tratamento da Reforma Agrária. $\mathrm{O}$ acesso à terra parece ser um objetivo comum entre os países, ainda que exista tratamento diferenciado levando em consideração as peculiaridades históriconacionais. Cabe observar, entretanto, como se dá a concepção de Direitos Humanos no âmbito do MERCOSUL e se essa noção se dá de forma a (potencialmente) viabilizar o acesso à terra como um Direito Humanos Universal.

\section{DIREITOS HUMANOS NO MERCOSUL}

Para que a Reforma Agrária seja compreendida em sua totalidade, é preciso pautar seu planejamento e implantação pelos Direitos Humanos. Tal abordagem faz-se necessária porque a democratização do acesso à terra no campo almeja promover a Justiça Social através da moradia, do trabalho, alimentação, saúde dentre outros direitos fundamentais. Percebe-se 
que, apesar de não estar expressamente delineada nas legislações dos países do MERCOSUL, a Reforma Agrária ampara-se nos Direitos Humanos para justificar seus ideais e métodos de abordagem. Estabelecendo políticas e ações em conjunto a serem adotadas por seus membros, pretende-se criar um ambiente propício na América do Sul ao desenvolvimento social, cultura e econômico, abrangendo iniciativas comuns relacionadas ao trabalho, educação, saúde, alimentação, dentre outros, além do mútuo auxílio dos países para que se possa lograr êxito.

Os Direitos Humanos são todos aqueles direitos intrínsecos à pessoa humana, correspondendo a um mínimo de existência (não mera sobrevivência), bem como sustentam a convivência pacífica e harmônica da sociedade, tanto no âmbito nacional quanto internacional. Ora, caso ocorra a inobservância dos Direitos Humanos estar-se-á diante de ambiente propício para conflitos armados, miséria, falta de condições mínimas de uma vida digna e plena. As principais características desses direitos são a universalidade, inalienabilidade, interdependência, indivisibilidade, sendo, também, não discriminatórios e igualitários, apresentando-se tanto como direitos quanto obrigações perante os Estados. A Organização das Nações Unidas - ONU define:

Human rights are rights inherent to all human beings, whatever our nationality, place of residence, sex, national or ethnic origin, colour, religion, language, or any other status. We are all equally entitled to our human rights without discrimination. These rights are all interrelated, interdependent and indivisible.

Universal human rights are often expressed and guaranteed by law, in the forms of treaties, customary international law, general principles and other sources of international law. International human rights law lays down obligations of Governments to act in certain ways or to refrain from certain acts, in order to promote and protect human rights and fundamental freedoms of individuals or groups. ${ }^{9}$ (UNITED NATIONS, [s.d.])

É imprescindível que os Estados encarem os Direitos Humanos como garantias e desafios a serem aceitos e solucionados por seus governantes e cidadãos, não somente como obrigações ou limitações, eis que esses diretos identificam espaços de integridade e pontos essenciais a serem reconhecidos a todos os seres humanos por sua simples existência, sendo impensável impor qualquer restrição ou condição para sua efetivação (BARROSO, 2010, p. 253). Ademais, esses direitos expressam o respeito e consideração de um indivíduo pela coletividade e vice-versa, bem como é possível sua identificação e compreensão um elemento de cada vez, mas nunca podem separados uns dos outros ou isso acabaria por ferir a dignidade da pessoa humana e, por consequência, a efetivação dos Direitos Humanos (CAGNONI, 2003, p. 65-68).

É interessante observar, como destacado por Jacqueline Pitanguy e Rosana Heringer, as relações entre os membros do bloco, porquanto o aprofundamento dos laços nacionais dentro deste bloco regional levará os países-membros a buscarem soluções em conjunto e equalização de dispositivos jurídicos internos (além de acordos entre si) para dar continuidade ao processo de integração. Neste caso, este estudo comparativo possui grande valia, principalmente para que a troca de influências ocorra sempre se espelhando nos instrumentos legais mais democráticos e

garantida por lei, na forma de tratados, lei internacional habitual, princípios gerais e outras fontes de direito internacional. Leis internacionais sobre Direitos Humanos determinam obrigações aos Governos para agir de certa forma ou se abster de praticar determinados atos com o objetivo de promover e proteger os Direitos Humanos e as liberdades fundamentais individuais ou coletivas." 
igualitários voltados para o pleno exercício dos Direitos Humanos. A Constituição Política de cada um desses países incorpora princípios que priorizam a pessoa humana e subordinam as atividades econômicas privadas ao respeito pelos direitos fundamentais do indivíduo e à consideração do interesse social. É evidente que a simples existência de uma nova Constituição, ainda que muito avançada, não é suficiente para que os Direitos Humanos sejam efetivamente respeitados, mas estabelece, no entanto, um patamar fundamental a partir do qual é possível avançar na elaboração de uma linguagem comum de direitos humanos no MERCOSUL. Estes países vêm ao longo dos últimos anos adotando relevantes Tratados Internacionais que, após devidamente ratificados pelos Estados, passam a ter força de lei, ampliando, assim, o sistema normativo de proteção aos Direitos Humanos vigente nos cenários nacionais. (PITANGUY; HERINGER, 2001, p. 19-20)

O bloco econômico em análise assinou em 20 de junho de 2005 o Protocolo de Assunção sobre o Quando, recepcionado pela legislação nacional como o Decreto 7.225 , de $1^{\circ}$ de julho de 2010, que promulga o Protocolo de Assunção sobre o Compromisso com a Promoção de Direitos Humanos no âmbito do MERCOSUL. Para auxiliar na execução desses compromissos assumidos o Instituto de Políticas Públicas em Direitos Humanos (IPPDH) ${ }^{10}$ e a Reunião de Altas Autoridades de Direitos Humanos e Chancelarias do Mercosul e Estados Associados (RAADH) atuam como âmbitos internacionais (constituindo, dessa forma, uma comunidade política), demonstrando que o MERCOSUL está preocupado com a promoção dos direitos

\footnotetext{
${ }^{10}$ De forma simplificada pode-se dizer que o IPPDH é um organismo regional ligado ao MERCOSUL que tem como ação a busca de parcerias, cooperação técnica, pesquisa, atividades formativas e apoio a ações de Direitos Humanos por todo o bloco. O IPPDH tem sede em Buenos Aires (Argentina), mas sua chefia se alterna entre os membros do Mercosul.
}

humanos como elemento de alcance do desenvolvimento. Assim, os países constantes do Cone Sul possuem características que os assemelham (especialmente dentro do contexto político):

\begin{abstract}
No decorrer dos anos 80, até os anos 90, as instituições democráticas foram reinstaladas, mas a exclusão dos pobres, não-brancos e mulheres continua, apesar de esforços para se construir uma sociedade mais inclusiva; 2) Hoje estes países são governados por regimes democráticos e a sociedade civil não mais detém o monopólio do discurso de defesa dos direitos humanos. (PITANGUY; HERINGER, 2000/2001, p. 52)
\end{abstract}

Os autores destacam que os governos latino-americanos, atualmente, de igual forma, trabalham os direitos humanos de uma forma diferente das organizações não governamentais, e que o tema estar nas pautas dos discursos não representa necessariamente implantação ou efetividade. Como afirmado pelos autores, "existe uma lacuna entre a linguagem internacional de direitos humanos, a retórica governamental e a proteção concreta destes direitos", e que tal lacuna (sua dimensão) "está relacionada ao poder e à política e é resultado das tensões, lutas e alianças de numerosos atores nacionais e internacionais" (2000/2001, p. 52). Um dado interessante é que nos países sul-americanos houve um aumento do número de OSCs (autodenominadas organizações de Direitos Humanos) voltando suas pautas para "questões de violência de gênero, direitos sexuais e reprodutivos, saúde e direitos humanos, raça e etnia, meio ambiente, direitos trabalhistas, proteção dos direitos das crianças, entre outras questões". 11

Nota-se que, existe uma tentativa de troca de informações (aproveitando mecanismos

\footnotetext{
${ }^{11}$ Em contrapartida os autores observam que as organizações tradicionais (dedicadas à luta pelos direitos humanos) permanecem ligadas ao tema das violações de direitos civis e contra a violência perpetrada pelo Estado, mesmo que tenham procurado ampliar suas ações em outras perspectivas $(2000 / 2001$, p. 52$)$.
} 
modernos) vez que não há uma contínua agenda de encontros dentro da rede de direitos humanos da América Latina. É interessante observar que cada país atua de forma diferente, pois a Argentina mantém uma Assembleia permanente de Direitos Humanos enquanto no Brasil existe esmagadora presença de organizações de direitos humanos que atuam de forma independente, tendo o Movimento Nacional de Direitos Humanos a função de agir como uma rede de informações entre elas (PITANGUY; HERINGER, 2001, p. 52).

\section{ACESSO A TERRA COMO DIREITO HUMANO E POLÍTICAS NO MERCOSUL}

Conforme exposto até aqui, percebe-se que a questão agrária no MERCOSUL, e de semelhante maneira na América Latina, desenvolveu-se na história como uma relação marcada por conflitos ideológicos, políticos e armados. A concentração da distribuição e posse das terras em poucas pessoas, a inércia legislativa e política cumuladas com suas ações desvirtuadas acabaram por relegar as famílias do campo a sua própria sorte (MARTINS, 1999, p. 97-102). Isso ocorreu invariavelmente, fosse pela criação de latifúndios no período colonial por meio de concessões de terras pela monarquia a aqueles com relevância social, política ou econômica (Brasil), fosse pela tomada de terra por meio da força ou sua aquisição a preços "mais camaradas" aos apoiadores dos líderes sul-americanos, ávidos pelo apoio de investidores externos a financiar seus governos (Argentina). Ou, ainda, pela tentativa a fórceps de implantar políticas voltadas ao desenvolvimento do campo, como a Reforma Agrária, de maneira impensada, forçando seu avanço somente pela perspectiva de legisladores leigos aos assuntos essenciais à vida no meio rural, causando instabilidade em toda sociedade e atingindo o objetivo totalmente oposto ao almejado: a deterioração da situação agrária (Chile).

É possível afirmar que a agricultura familiar entre os países que compõem o MERCOSUL apresenta características similares: se enquadram, em uma perspectiva geral, no marco de políticas públicas destinadas à redução da participação do Estado na economia, apoio à modernização da produção para o mercado, e incentivo à exportação (BRASIL, 2006, p. 14). Convém acrescentar também que é preciso conciliar a Reforma Agrária com os anseios dos trabalhadores rurais, porquanto, além de serem os maiores afetados pela mudança no sistema agrário vigente, o próprio acesso a terra é voltado para as famílias rurais, essas que não foram recepcionadas com condições mínimas de possuir e desenvolver uma porção de terra para seu sustento e moradia. Para tanto, José Graziano da Silva explica com propriedade que a Reforma Agrária deve ser ampla, ou seja, efetivada em todo território em que se está desenvolvendo, com a intenção de evitar que seja utilizada como barganha para amenizar tensões ou forma de intimidar as classes que necessitam do acesso a terra para sobreviver. Ademais, deve ser massiva, de forma que se proporcione acesso à terra pelas inúmeras famílias que não possuem nenhuma ou pouca terra para sobreviver ou sustentar-se, excluindo assim a possibilidade de favorecer interesses de determinadas pessoas ou grupos. Acrescenta ainda que deve ser imediata, com elaboração e controle de metas a serem atingidas no menor espaço de tempo possível. E, também, deve ser com o controle dos trabalhadores, em especial os rurais já que este que são os maiores afetados e interessados para assim, evitar-se-á que a reforma agrária seja elaborada por burocratas, detentores do poder, entre outras pessoas que não tem real interesse na terra fora o econômico (SILVA, 1985, p. 34-37).

O motivo para que tal medida seja adota centra-se na necessidade de encarar o acesso à 
terra proporcionado pela Reforma Agrária no MERCOSUL como um Direito Humano para as famílias que habitam o campo. Como previamente explicado ao conceituá-los, Direitos Humanos são interdependentes, indivisíveis, universais, inalienáveis e igualitários, necessitando uns dos outros para sua mútua efetividade, sendo inviável sua separação para o alcance da dignidade da pessoa. Esta, por sua vez, invoca uma vida digna de ser usufruída, não meramente a sobrevivência de cada dia, sem preconceitos ou discriminação motivada por origem, raça, sexo, ou quaisquer outras formas de exclusão e estigmatização. Assim, a dignidade de cada indivíduo não pode ser valorada ou mesmo medida, mas é impossível que seja renunciada (pela própria pessoa) ou alienada (por terceiros) sem que incorra em grave violação aos Direitos Humanos.

Ora, é clara a figura do acesso à terra como um Direito Humano para as famílias rurais, especificamente como a dignidade da pessoa humana A partir do momento que as famílias rurais obtenham uma porção de terra como sua, supre-se a moradia logo de início. Após, com o desenvolvimento da propriedade, obter-se-á a segurança alimentar e a possibilidade de comercializar a produção, alcançando o direito ao desenvolvimento. Aqui não se trata de grande produção nacional ou para exportação, mas tão somente a agricultura familiar e a pequena propriedade que vendem os seus excedentes, ou o que podem dispor, para o incremento da renda familiar. Na sequência, poderá ser suprida a educação, a saúde, a segurança, buscar exercer e preservar sua identidade cultura e particular, participar da sociedade em que vive como um cidadão reconhecidamente dotado de direitos e deveres, assim por diante. Nas palavras de Fernando Kosovsky e Nicolás Soler (2004, p. 280-281): “[...] la tierra es la 'madre' que hace posible el cultivo y la cría de animales, la base de la alimentación y de la provisión de recursos."
Visto isso, torna-se imprescindível a ação legislativa por parte dos políticos e governantes para proporcionar métodos de regularização da posse ou redistribuição da terra, promovendo, assim, tanto a Justiça Social quanto a produção racional e que preserve o meio-ambiente.

Felizmente, não é somente a Reforma Agrária que o MERCOSUL almeja. Organizandose e elaborando políticas públicas e ações em conjunto, objetiva-se proporcionar o acesso à terra a todos os que vivem no âmbito agrário da América do Sul, posteriormente da América Latina e no mundo.

Em suas Declarações Finais, a XVII Cúpula Social do MERCOSUL, realizada entre 14 a 16 de julho de 2016, exalta seus membros e associados a desenvolverem novas abordagens coletivas para a utilização de seus recursos naturais enquanto preservam o meio-ambiente, tido como "a mãe terra" (MERCOSUL, 2015, p. 2). Através da união entre o Estados e a integração de seus cidadãos, busca-se combater a redução $\mathrm{e}$ cerceamentos de direitos das minorias, como famílias rurais, negros, mulheres, dentre outros. Democraticamente, essas parcelas sociais historicamente oprimidas devem unir-se aos movimentos sociais para reivindicar seus direitos como ser humano e não se deixar intimidar pela repressão e violência empregada por aqueles que detêm a supremacia econômica e política. Ainda, exalta o MERCOSUL a solidificar sua base rumo a um bloco justo e democrático, garantindo o acesso aos Direitos Humanos através do trabalho, saúde, fim da discriminação e preconceito, proteção ambiental, desenvolvimento econômico e social voltado ao bem comum, dentre outros diversos temas extremamente sensíveis para a criação de uma comunidade latino-americana. Cita-se o tópico relativo ao tema da questão agrária:

13. Reafirmamos os territórios, terra, água, sementes, biodiversidade e direitos dos povos do campo, das águas e das florestas como a base de um 
projeto de desenvolvimento baseado na justiça social e ambiental. Entretanto, essa base está sob continuo ataque graças a uma ofensiva do agronegócio, das empresas mineradoras, petroleiras, das corporações transnacionais, das compras de terras por estrangeiros e da especulação imobiliária, colocando em risco a existência da própria humanidade, pois compromete a reprodução da vida em todas suas dimensões. Conclamamos os Estados a garantir a reforma agrária popular e integral e a demarcação e homologação de terras indígenas e de populações tradicionais como forma de reparar as grandes dívidas sociais da América do Sul e recolocar o desenvolvimento regional sobre outros patamares, como a agroecologia e a soberania alimentar. Conclamamos os Presidentes a implementar as recomendações apresentadas pela Reunião Especializada sobre Agricultura Familiar (REAF) e pela Reunião Especializada sobre Cooperativismo (RECM). (MERCOSUL, 2015, p. 5)

Assim, em apertada síntese, o acesso à Terra proporcionado pela Reforma Agrária pode e deve ser compreendido como um Direito Humano para as famílias rurais, da mesma maneira como o MERCOSUL passou a compreender a questão. Conclui-se nesse sentido pela relação pessoal entre o indivíduo e a propriedade, baseada na importância e no significado que a posse de terra representa, tratando-se desde o sustento e abrigo até a espiritualidade, não somente a propriedade em si (REIS, 2012, p. 120).

\section{CONCLUSÃO}

A análise da temática agrarista envolve uma necessária concepção da realidade social e jurídica de um país, o que exige uma compreensão nem sempre fácil ou possível. Fazer essa leitura tendo em vista países distintos apresenta um desafio ainda maior pelo reconhecível estranhamento de realidades. O MERCOSUL padece ainda de pouco estudo no que tange ao universo agrário, pois se nota a forte tendência a avaliar as ações do bloco econômico apenas na perspectiva comercial, econômica e política, sem "descer" tal visão para relações do homem com a terra e o acesso à terra. Nesse sentido, a discussão do acesso à terra como um direito humano ainda se encontra pouco estudado e, como se observa, merece maior atenção de pesquisadores e da própria comunidade acadêmica (especialmente a dedicada aos estudos jurídicos).

Partindo de noções ligadas ao Estado, Direito Agrário, Direitos Humanos e Reforma Agrária abordadas neste artigo, diga-se, de forma sucinta e apenas inicial, contempla-se uma necessidade de compreensão das relações do MERCOSUL enquanto bloco e da sua responsabilidade quanto à Reforma Agrária em seus países membros. O desenvolvimento do bloco econômico não pode prescindir do desenvolvimento do homem do campo, da econômica ligada à produção agrícola e dos direitos humanos que não raras vezes são desrespeitados no espaço agrário.

É possível notar a existência de lacunas conceituais na doutrina sobre o estudo da Reforma Agrária numa perspectiva comparada dos países da América do Sul, por juristas, encontrando tais pontuações notadamente nas pesquisas sociológicas, históricas ou similares. $\mathrm{O}$ mesmo se diz da Reforma Agrária e do Direito à terra que está presente nos discursos nacionais há muito; possui grande incidência fática, bem como importância política, mas se verifica pouca reflexão jurídico-doutrinária.

Nota-se, ainda, que, como pontuado no artigo, existam órgãos do MERCOSUL ligados aos direitos humanos, porém o bloco segue sendo omisso e ineficaz no que se refere aos temas de reforma agrária, direitos do homem do campo e do acesso à terra. Como observado, a função do bloco deve transcender a mera circulação de mercadorias e pessoas e alcançar o patamar de integração e desenvolvimento que permita o 
crescimento qualitativo de todos os países membros ${ }^{12}$.

Por fim, é importante destacar que a presente pesquisa não se pretende exaustiva ou conclusiva em suas considerações, pretendendo apenas a função de reflexões iniciais, introduzindo (ou ao menos reforçando e atualizando) o debate no cenário jurídico atual, talvez como um incentivo para novos debates e discussões. Há que se reconhecer que o presente estudo possui limitações decorrentes da própria complexidade e amplitude da matéria enfrentada (multidisciplinariedade e grande relevância social e jurídica), não podendo prescindir de análises constantes e sempre reatualizadas. O resultado das análises apresenta limitações temáticas e de abordagem, não havendo espaço suficiente para reflexões a respeito da jurisprudência sobre o assunto, ou das legislações agraristas de cada país, por exemplo.

Destarte, insta salientar que o tema é instigante e se apresenta como elemento estratégico para o desenvolvimento local, nacional e do bloco MERCOSUL, com repercussão na própria América do Sul. Na análise se identifica que o tema do acesso à terra como um direito humano deve ser garantido no direito positivado dos países do bloco e que o MERCOSUL tem uma função chave no fortalecimento dessa proposta.

\section{REFERÊNCIAS}

ARGENTINA. Constitución. Constitución de la Nación Argentina. Santa Fe de la Vera Cruz, Santa Fe, 22 de agosto de 1994. Disponível em: < http://www.senado.gov.ar/deInteres>. Acesso em: 25 jun. 2016.

ARGENTINA. Ministerio de Justicia y Derechos Humanos. Secretaría de Derechos Humanos, [s.d.]. Los Derechos Humanos: ¿Qué son los derechos humanos? Disponível em: $<$ http://www.jus.gob.ar/derechoshumanos/los-derechos-humanos/\%C2\%BFque-son-los-derechoshumanos.aspx>. Acesso em: 20 jun. 2016.

BARROSO, Luís Roberto. Curso de Direito Constitucional Contemporâneo: os conceitos fundamentais e a construção do novo modelo. 2. ed. São Paulo: Saraiva, 2010.

BAUER, Guilherme G. Télles. Sobre as origens da questão agrária brasileira. Revista de História Regional, Ponta Grossa, UEPG, v. 3, n. 1, 135-166, verão 1998. Disponível em: $<$ http://www.revistas2.uepg.br/index.php/rhr/article/view/2056/1538>. Acesso em: 29 jun. 2016.

BRASIL. Constituição (1988). Constituição da República Federativa do Brasil, Brasília, DF, 05 de outubro de $1988 . \quad$ Disponível em: $<$ http://www.planalto.gov.br/ccivil_03/constituicao/ConstituicaoCompilado.htm>. Acesso em: 20 jun. 2016.

BRASIL. Estatuto da Terra. Lei $n^{\circ} 4.504$ de 30, de novembro de 1964. Dispõe sobre o Estatuto da Terra e dá outras providências. Diário Oficial da União, 30 nov. 1964. Disponível em: $<$ http://www.planalto.gov.br/ccivil_03/leis/L4504.htm>. Acesso em: 27 jun. 2016.

BRASIL. Instituto Brasileiro de Cidadania e Reforma Agrária, [s.d.]. Reforma Agrária. Disponível em: $<$ http://www.incra.gov.br/reforma_agraria>. Acesso em: 27 jun. 2016.

\footnotetext{
${ }^{12}$ A omissão do Mercosul também se nota em outras áreas (educação, saúde, política de pleno emprego, etc.), se notando as ações do bloco predominantemente ligadas ao

comércio internacional (políticas de importação e exportação). 
BRASIL; MERCOSUL. Saiba mais sobre o MERCOSUL, [s.d.]. Disponível em: $<$ http://www.mercosul.gov.br/index.php/saiba-mais-sobre-o-mercosul>. Acesso em: 23 jun. 2016.

BRASIL. Ministério das Relações Exteriores, [s.d.]. Integração Regional: MERCOSUL. Disponível em:

$<$ http://www.itamaraty.gov.br/index.php?option $=$ com_content\&view $=$ article\&id $=686$ :mercosul\&cati $\mathrm{d}=143 \&$ lang=pt-BR\&Itemid=434>. Acesso em: 23 jun. 2016.

BRASIL. Ministério do Desenvolvimento Agrário. Gênero, agricultura familiar e reforma agrária no Mercosul. Brasília: Ministério do Desenvolvimento Agrário, 2006. Disponível em: $<\mathrm{http}$ ://www.iicabr.iica.org.br/wp-

content/uploads/2014/03/Genero_agricultura_familiar_reforma_agraria_Mercosul.pdf $>$. Acesso em: 13 jul. 2016.

CARRERA, Rodolfo Ricardo. El Derecho Agrario en las Leyes de Reforma Agraria de America Latina. Revista de Estudios Agrosociales, n. 48, p. 131-169, 1964. Disponível em: $<$ http://www.magrama.gob.es/ministerio/pags/Biblioteca/Revistas/pdf_reas\%2Fr048_03.pdf >.

Acesso em: 27 jun. 2016.

CHILE. Biblioteca Nacional de Chile. La tierra para el que la trabaja: La Reforma Agraria (1962 1973), 2015. Disponível em: <http://www.memoriachilena.cl/602/w3-article3536.html\#presentacion>. Acesso em: 27 jun. 2016.

COMPARATO, Fábio Konder. Ética: Direito, moral e religião no mundo moderno. São Paulo: Companhia das Letras, 2006.

CORREDOR, Renan Juan Duque. Trascendencia histórico-jurídica de la Ley de Reforma Agraria venezolana del 5 de marzo de 1960. Revista de la Procuraduría Agraria, n. 42, México, p. 137-152, 2009.

Disponível

em:

$<$ http://www.pa.gob.mx/publica/rev_42/ANALISIS/Rom\%C3\%A1n\%20Duque_9.pdf $>$. Acesso em: 28 jun. 2016.

FERREIRA, Pinto. Curso de Direito Agrário. 5. ed. rev. e atual. São Paulo: Saraiva, 2002.

FILHO, Francisco Cláudio Oliveira Silva. A Reforma Agrária na Constituição de 1998 e o Desenvolvimento Econômico do Brasil. In: XXI ENCONTRO REGIONAL DE ESTUDANTES DE DIREITO E ENCONTRO REGIONAL DE ASSESSORIA JURÍDICA UNIVERSITÁRIA: 20 ANOS DE CONSTITUIÇÃO: PARABÉNS! POR QUÊ?, 2008, Crato. Anais do $21^{\circ}$ Encontro Regional de Estudantes de Direito e Encontro Regional de Assessoria Jurídica Universitária. Ceará: XXI ERED/ERAJU, 2008.

FIAN Y LA VÍA CAPESINA. Campaña Global por la Reforma Agraria: Informe de la Misión de Investigación argentina, 2004.2 Disponível $<$ http://www.fian.org/fileadmin/media/publications/Informe-de-la-Mision-de-Investigacion-aArgentina-2004.pdf $>$. Acesso em: 26 jun. 2016.

KOSOVSKY, Fernando; SOLER, Nicolás. Perspectivas del trabajo jurídico sobre el derecho a la tierra en Argentina. El outro derecho, Bogotá, n. 31-32, p. 273-297, 2004. 
LEITE, Sérgio Pereira; AVILA, Rodrigo Vieira de. Reforma agrária e desenvolvimento na América Latina: rompendo com o reducionismo das abordagens economicistas. Rev. Econ. Sociol. Rural, Brasília, v. 45, n. 3, p. 777-805, set. 2007. Disponível em: <http://dx.doi.org/10.1590/S0103$20032007000300010>$. Acesso em: 03 jul. 2016.

MERCOSUL. Declaração Final - XVIII Cúpula Social do Mercosul Brasília, 14, 15 e 16 jul. 2015. Brasília, 2015. Disponível em: <http://flacso.org.br/files/2015/07/DECLARACAO-FINAL-XVIIIC\%C3\%BApula-Social-do-Mercosul.pdf>. Acesso em: 28 jun. 2016.

MARÉS, Carlos Frederico. Função Social da Propriedade. In: SONDA, Claudia; TRAUCZYNISK, Silvia Cristina. Reforma Agrária e Meio Ambiente: Teoria e Prática no Estado do Paraná. Curitiba, 2010. Disponível em: <http://www.itcg.pr.gov.br/modules/conteudo/conteudo.php?conteudo=79>. Acesso em: 27 jun. 2016.

MARIANO, Karina Pasquariello. Globalização, integração e o estado. Lua Nova, São Paulo, n. 71, p. 123-168, 2007. Disponível em: <http://dx.doi.org/10.1590/S0102-64452007000200005>. Acesso em: 28 jun. 2016.

MARTINS, José de Souza. Reforma Agrária: o impossível diálogo da História possível. Tempo Social, São Paulo, v. 11, n. 2, p. 97-128, 1999.

PESCATORE, Pierre. Derecho de la integración: nuevo fenómeno en las relaciones internacionales. Tradução de Inés Carmen Matarese. Buenos Aires: INTAL, 1973.

PITANGUY, Jacqueline; HERINGER, Rosana Rodrigues (Org.). Direitos Humanos no Mercosul. 1. ed. Rio de Janeiro: CEPIA, 2001. 174p. Disponível em: $<$ http://www.cepia.org.br/doc/livro4forum.pdf>. Acesso em: 26 jun. 2016.

PITANGUY, Jacqueline; HERINGER, Rosana Rodrigues. Subsídios para uma agenda de direitos humanos no Mercosul. Revista Proposta, Rio de Janeiro, n. 87, p. 60-66, 2000. Disponível em: $<$ http://www.rolim.com.br/2002/_pdfs/jaqueline.pdf $>$. Acesso em: 26 jun. 2016.

REBORATTI, Carlos. Reforma agraria en la Argentina: entre la utopía y la indiferencia. In: Actas del II Encuentro de Geógrafos de America Latina, Tomo II: Reforma agraria y problemas campesinos, Montevideo, $1989 . \quad$ Disponível em: $<$ http://observatoriogeograficoamericalatina.org.mx/egal2/Geografiasocioeconomica/Geografiaagrari a/02.pdf>. Acesso em: 26 jun. 2016.

REIS, Rossana Rocha. O Direito à Terra como um Direito Humano: a Luta pela Reforma Agrária e o Movimento de Direitos Humanos no Brasil. Lua Nova, n. 86, São Paulo, p. 89-122, 2012.

RIBEIRO, Vanderlei Vazelesk. Paraguai: um golpe de novo tipo e a permanente questão agrária. Tempo Presente, Rio de Janeiro, n. 2, p. 1-12, 2012. Disponível em: <http://www.seer.ufs.br/index.php/tempopresente/article/view/4227>. Acesso em: 28 jun. 2016.

SILVA, José Graziano. Reforma Agrária. Lua Nova, São Paulo, v. 1, n. 4, p. 34-37, 1985. Disponível em: $<$ http://www.scielo.br/scielo.php?pid=S0102-64451985000100012\&script $=$ sci_arttext $>$. Acesso em: 27 jun. 2016. 
STREDEL, Juan. Trece años de Reforma Agraria em Venezuela. Nueva Sociedad, Buenos Aires, n. 6, p. 44-50, 1973. Disponível em: <http://nuso.org/articulo/trece-anos-de-reforma-agraria-envenezuela/>. Acesso em: 27 jun. 2016.

UNITED NATIONS. Oficce of the High Comissioner for Human Rights, [s.d.]. Your Human Rights: What are Human Rights? Disponível em: $<$ http://www.ohchr.org/EN/Issues/Pages/WhatareHumanRights.aspx>. Acesso em: 27 jun. 2016.

VENTURA, Deisy; ROLIM, Marcos. Os direitos humanos e o Mercosul: uma agenda (urgente) para além do mercado. In: Marcos Rolim - direitos humanos e segurança. [S.1.: s.n.], [200-]. Disponível em: $<$ http://www.rolim.com.br/2002/_pdfs/dhmercosul.pdf>. Acesso em: 15 jun. 2008.

Recebido em: 15/09/2016

Aceito em: 27/12/2016 
